\title{
Introduction: international drug policy in an era of growing complexity, challenge and tension David R. Bewley-Taylor and Khalid Tinasti
}

Varying patterns of stability and dynamism tend to characterize public policy across a range of domains. Drug policy, as an exemplar of a cross-cutting issue, is no exception. In many parts of the world, the last ten years or so have witnessed unprecedented - in some cases rapid in others more incremental - shifts away from the traditional law enforcement dominated approach to dealing with multiple facets of illegal drug markets. Elsewhere stasis, or even retrenchment, better characterizes the policy landscape. While impossible to neatly categorize such differences in approach, with many nations falling somewhere in-between, the growing mosaic of policy responses have to a greater or lesser extent been influenced by the increasingly complex and expanding nature of what has become known simply as the 'world drug problem'.

Reflecting a growing understanding of what by its very nature is a difficult market to quantify, the United Nations Office on Drugs and Crime (UNODC or Office) noted in the Preface to the 2019 World Drug Report, 'The findings of this year's' flagship publication, 'fill in and further complicate the global picture of drug challenges' (UNODC, 2019, p. 1). The Report goes on to stress that in 2017 an estimated 271 million people, or 5.5 per cent of the global population aged 15-64, had used drugs in the previous year; a figure 30 per cent higher than in 2009 (UNODC, 2019, p. 7). Moving beyond simple prevalence figures, an issue discussed in detail at various points within this Research Handbook, UNODC also notes how an estimated 35 million people suffer from what it refers to as 'drug use disorders', with an estimated 585,000 people dying 'as a result of drug use in 2017' (UNODC, 2019, pp. 1 \& 19). Within the context of these figures, as well, as among other things, fluctuations in drug crop cultivation, shifting and increasingly complex trafficking patterns (including in relation to illegal cryptomarkets), the continued emergence of new psychoactive substances (NPS), a growing trend in the manufacture, trafficking and use of Amphetamine Type Stimulants in some parts of the world, an ongoing boom, particularly in North America, in the synthetic opioid market, under resourcing of appropriate public health responses and minimal access to controlled essential medicines for the management of pain and other conditions in some parts of the world, the Office noted on the Report's launch, that the 'Severity and complexity of the World Drug Situation [is] increasing' (IDPC-GDPO, 2019, p. 2). Faced with this picture, the International Narcotics Control Board (INCB) noted in the Foreword to the Board's Report for 2019 that 'We stand at a challenging point in drug control' (INCB, 2020, p. iv).

It is difficult to disagree with this perspective. Moreover, the dynamic state of drug markets and policy interventions designed to address them are certainly fascinating areas of study for those working in and across a range of academic disciplines. Yet, beyond academia, these conjoined issues arguably stand out among an array of other public policy concerns due to the profound impact they have on the lives of millions of individuals and the communities within which they live. Its unusual ubiquity makes it likely that most readers will, in one way or another, have been touched by the 'illegal drugs' phenomenon. 
Variation of experience reflects the complex drivers behind engagement in all aspects of the illicit market, from drug crop cultivation to drug use, whether the latter results in problematic drug use or otherwise. The potential harmfulness of a variety of psychoactive substances, currently and variously categorized as both licit and illicit, should not be underestimated. Nonetheless, there is a growing appreciation in many jurisdictions - based on surveillance, monitoring and existing evidence - national and subnational, that much drug-related harm is often the result of policy interventions intended to 'solve' the drug problem. At the United Nations (UN) level, these have been called the 'unintended consequences' of drug policy (Costa, 2008). Parallels here might be drawn with iatrogenic harm within a medical setting when the interventions of physicians sometimes generate additional or greater illness to the patient.

While this is the case, a substantial number of authorities - across a range of political systems - have approached growing and increasingly multifaceted drug markets by keeping faith in the 'war on drugs': shorthand for a predominantly supply oriented approach based on punitive prohibition and a reliance on law enforcement, and in some cases military, interventions. The underpinning logic, identifiable at the international level since at least the 1960s but particularly since the early 1970s and the pronouncements of US President Richard Nixon, is that the best way to remove harms, variously perceived, associated with the illegal drug market is to work towards the reduction of its size and its ultimate elimination. Although debate surrounds the status of the slogan within the UN, the concept arguably reached its global apogee when the international community met at the UN General Assembly Special Session on Drugs (UNGASS) in 1998 under the banner 'A Drug Free World. We can do it!'

Reflecting growing and multifaceted tensions faced by some nation states between pronouncements made at international forums and policy approaches implemented on the ground, it is instructive to see how this perspective remains prominent within the UN's most recent substantive soft law instrument relating to drugs. Among a range of commitments to broader UN principles and values, the 2019 Ministerial Declaration states, 'We reiterate our resolve, in the framework of existing policy documents, inter alia, to prevent, significantly reduce and work towards the elimination of illicit crop cultivation and the production and manufacture of, trafficking in and abuse of narcotic drugs and psychotropic substances, including synthetic drugs and new psychoactive substances' (emphasis added) (UN, 2019).

Indeed, while in no way claiming a direct causal relationship between the international drug control regime based on three UN drug control conventions and a 'war on drugs' approach pursued by many nation states, it is not unreasonable to suggest that the predominantly supply focused prohibitive outlook privileged by the regime, and long bolstered by the US, has played a critical role in sustaining a punitive approach in many parts of the world (Andreas and Nadelmann, 2006, Boister, 2016 and Babor et al., 2018, pp. 233-236). Representing a complex and varied interface between different levels of governance, it is fair to say that the influence of the overarching UN drug control framework comes into play in one way or another at some stage within processes of policy-making, implementation and review. Some interpretative flexibility certainly exists within the conventions. Nonetheless, among other things, their prohibition of the non-medical and non-scientific use of internationally controlled substances cannot be ignored. As Babor and colleagues note, 'Most international treaties deal with relations between nations, but the drug treaties also hold substantial implications for domestic legislation' (Babor et al., 2018, p. 229).

Drivers for the ongoing pursuit of a 'war on drugs' in many parts of the world are, as is the case across a range of policy choices, varied and complex. Some commonalities may be iden- 
tified, however. Despite an increasingly robust evidence base demonstrating the ineffectiveness of law enforcement dominated approaches in, for example, reducing drug market violence or increasing drug prices (Werb et al., 2011 and Pollack \& Reuter, 2014), ideology, symbolism and the related targeting of marginal groups tend to take precedence. A 'tough on drugs' approach remains politically persuasive in many parts of the world with drugs often regarded by authorities as the 'useful enemy' (Christie \& Bruun, 1991). This results in high levels of criminalization and incarceration, especially for low-level non-violent offenders, and in extreme cases use or threat of the death penalty for drug-related offences. This remains the case even though, after 'decades of policies that rely on harsh punishment, and the threat and spectacle of executions, there is no evidence that the death penalty has any unique deterrent effect on either the supply or use of controlled substances. In fact the opposite appears to be true' (Girelli, 2019). In some countries extrajudicial killings have also been a tolerated feature. The most recent example, and one arguably related to the emergence of 'strongman' populist politics, relates to the Philippines under the presidency of Rodrigo Duterte. Ongoing enthusiasm for the country's stringent approach could be seen at the 2019 meeting of the Commission on Narcotic Drugs (CND), the UN's central policy-making body on drug-related matters. Then, while admitting that there had been some abuses, a member of the Philippine delegation stated that these were 'no reason to stop the war on drugs'. Moreover, he continued, the war had emerged out of a drug plan that had lasted for years - 'we just gave it a longer blade and wider swing' (IDPC, 2019, p. 7). As noted in an account of the Commission's meeting, 'The violence of this rhetoric was genuinely startling, heard as it was at the heart of the United Nations' (IDPC, 2019, pp. 7-8). For those individuals within the Philippines or elsewhere encountering the newly sharpened edge of such draconian drug control policy, any notion that we have entered a post 'war on drugs' era must appear little more than the product of an obscure academic exercise.

As this volume shows, however, while punitive prohibition is far from a thing of the past the drug policy landscape is becoming increasingly variegated and polarized. Admittedly an outlier on the broad spectrum of drug policies, pronouncements like that of the Filipino delegate present in stark relief the growing, and manifold, tensions that exist around the issue area and the gulf now separating policy approaches in different parts of the world. Influenced by the growing scientific evidence base on not only the properties of various psychoactive substances but also the effectiveness, or otherwise, of policy interventions intended to address the illicit market for them, many jurisdictions have been moving away from the quixotic goal of market elimination, a reoccurring theme within the pages that follow. Although perhaps not overtly presented in such terms, such a shift in policy implicitly engages with more nuanced conceptual frameworks based around ideas like 'wicked problems' and market management (Bewley-Taylor, 2016).

In addition to concerns for cost effectiveness, policy shifts have in recent years been increasingly influenced by a growing understanding of an array of tensions between traditional prohibition dominated and law enforcement oriented approaches and the human rights obligations of states, obligations derived from a range of international legal instruments and, more recently, operationalized via UN system-wide initiatives like the 2030 Sustainable Development Agenda and its Goals (SDGs). Within this context, many states - or subnational units within them - are moving towards, or continuing to prioritize, public health and individual rights over punitive prohibition. Again, as they have been for many years, the imperatives for such changes are many, varied and seldom politics free. For example, engagement in some, predominantly although not exclusively European, countries with and the scaling-up of the 
harm reduction approach and related interventions since the 1980s has been largely driven by concern for the transmission of HIV among people who inject drugs. Meanwhile, in relation to various waves and varieties of decriminalization of drug possession for personal use since the 1970s, some governments around the world have reduced 'harsh penalties for drug offences to save costs', while others have increased 'their harm reduction and public health measures in an effort to properly address problematic drug use' (Eastwood, Fox \& Rosmarin, 2016, p. 6). Resulting from both bottom-up and top-down political processes, similar imperatives can be seen to underpin shifts since 2012 towards legally regulated markets for the production, sale, possession and non-medical adult use of cannabis in Uruguay, Canada and, at a subnational level, the US.

The still limited, but hugely symbolic and - in terms of international law - legally challenging, shift towards regulated cannabis markets represents a particularly heated flashpoint within international drug policy debate (Bewley-Taylor, Jelsma \& Blickman, 2014). Yet over the course of recent years, few international meetings on drug policy, particularly within the CND, have been free from increasingly tense and critical debate about the perceived merits, or otherwise, of different policy approaches (IDPC, 2019). In Vienna, the home of the UN drug control apparatus, the Russian Federation, now the dominant defender of punitive prohibition, leads a diverse set of states in the protection of the traditional law enforcement dominated approach (Tinasti \& Barbosa, 2017). Such a bloc looks to agreed language within the 2019 Ministerial Declaration and its predecessor documents to bolster their stance. Meanwhile, conscious of their own obligations under the drug control treaties as well as broader UN values and principles, other more progressive states from different parts of the world look to the same instruments to legitimize and defend their domestic policy choices. As will be discussed, such interpretive variance and the growing tensions that accompany it do much to confirm the view that, while as with other transnational issues of concern there has never been a complete harmony of views, international consensus on drug policy is now arguably fractured as never before.

\section{AIMS AND OVERVIEW}

With this in mind, the core aim of this Research Handbook is to provide readers with the first comprehensive overview, or, mindful of the current fluidity surrounding the issue, snapshot, of the drug policy landscape from a global perspective. This incorporates detailed discussion of increasingly complex and dynamic drug markets, a progressively more diverse and divided range of policy responses and the resultant political and ideological tensions that often emerge at both national and international levels. By bringing together into one volume analysis of the history and operational mechanisms of the extant international drug control system, a range of policy approaches pursued in different parts of the world, emerging tensions within the UN drug control system and some key future challenges we hope to provide not only a valuable resource for country, regional, internationally focused and thematic research, but also for a much needed comparative approach to the issue area (Coulson, 2019). Embracing a range of disciplinary approaches, the Research Handbook draws on the expertise and insightful perspectives of a range of prominent scholars, emerging early career researchers and practitioners from drug policy reform oriented civil society organizations. In order to ensure analytical tension and critique, it has been a deliberate approach from the beginning of the project in 2018 to bring together a group of contributors who are all, to varying degrees, critical of 
the status quo. With drug policy being an example of a cross-cutting public policy issue, the volume is intended for both academics and policy-makers across a variety of disciplines and fields with the hope that the wide-ranging chapters will not only contribute to and enhance the rapidly expanding drug policy literature, but also help better inform policy-makers on the scientific evidence surrounding the effectiveness of various policy approaches and their intersection, or otherwise, with human rights frameworks and obligations. The volume is divided into four sections, although while easily read as stand-alone pieces, a range of reoccurring themes means that chapters within each section should not be viewed as discrete contributions.

Part I, 'The history of international drug control', provides vital historical context for the entire volume. It helps to explain not only the origins of the underpinning mechanisms and guiding principles influencing contemporary drug policy, but also the political, cultural, commercial and social determinants of many current policy failures.

In Chapter 1, 'Foundations of the international drug control regime: nineteenth century to the Second World War', William B. McAllister outlines the principal factors contributing to national governments' negotiation of globally applicable rules that defined the boundaries of the licit drug trade. He argues that a centuries-old, increasingly robust, unregulated traffic in opium across Asia proved so problematic by the early twentieth century that states deemed it necessary to act. In forging a series of international treaties, governments protected domestic priorities, ensured low prices for medicinal substances, and focused on limiting the supply of the key agricultural raw materials: opium and coca. States sanctioned the creation of international regulatory bodies to track the licit trade and enforce the rules. In certain respects, the regime proved successful. Yet, McAllister demonstrates, the treaties also created incentives for entrepreneurial smugglers that fostered a permanent illicit traffic. As the chapter concludes, the first half of the twentieth century saw states determine the basic pitch of the playing field. And the fundamental thrust of those rules, institutions, and practices remain intact today.

Building upon McAllister's discussion, Chapter 2, 'The evolution of international drug control under the United Nations,' sees Constanza Sánchez-Avilés and Ondrej Ditrych provide a comprehensive overview of the evolution and operation of the international drug control under the auspices of the UN. Beginning with the transfer of responsibility for control from the League of Nations, it analyses, from a critical perspective, the adoption and implications of the three main international drug control conventions, as well as the role and operation of the drug control bodies that shape the UN drug control architecture. Finally, offering a theoretical contribution to the volume that moves analysis beyond norms and regime theory (Bewley-Taylor, 2012), it provides a novel critical reading of the UN drug control regime. In so doing and adopting a predominantly Foucauldian perspective, the authors present it as a 'dispositive' of heterogeneous ensembles of discourses, institutions, regulatory decisions, laws, scientific statements and moral propositions strategically oriented by a general line of force, and give special attention to metrics and statistics as key political tools to enforce drug control and to justify political choices.

Re-engaging with historical research, but continuing with a novel approach, Chapter 3 explores an often ignored facet of the drug control narrative; the drug consumer. Picking up on some of the ideas in Chapter 1, in 'Drug consumers and the formation of the international drug control apparatus', Christopher Hallam explores the role of the consumer in the generation of policy, focusing particularly on the foundational period of the international drug control apparatus. The smoking of opium in China, and its transfer into various national contexts through the migration of the Chinese diaspora, he argues, drove the movement towards 
restrictive controls. This was particularly the case when opium-smoking and other forms of drug use crossed the boundaries marking off immigrant enclaves and entered into sub-groups within the indigenous population. In short, Hallam concludes, in addition to the macro-power that forged nation states into a global field of drug control, the micro-powers and the field of intervention that they traversed drove the actions of the control apparatus through millions of tiny interventions.

Moving beyond, and beneath, discussion of the overarching international drug control framework, Part II seeks to explore market and policy dynamics operating at regional and country levels. In 'The geospatial dimensions of drug policy', chapters analyse the state of play, including necessary contextual scene-setting, within nation states in several geographical regions as well as parts of the 'Muslim World'.

Once again incorporating an important historical component and discussion of the intersections between domestic and international policy, Chapter 4 is titled 'North American drug policy: American and Canadian developments from the early twentieth century to today'. Here Katharine Neill Harris, traces the development of American and Canadian drug policy and includes a focus on early twentieth-century narcotics legislation, the American 'drug wars' of the 1970s and 1980s and the lasting impact US influence has had on international drug policy. The author argues that social constructions of drug use and the drug user have played a larger role in shaping drug policy than factual considerations about the problem of drug use, and that the differences in Canadian and US drug policy evident today are the product of distinct differences between the countries' history, values, and culture. The chapter concludes with a summary of American and Canadian drug policy developments in the twenty-first century and provides important context for more specific discussion in Chapter 17 of changes in cannabis policy.

The focus of attention in Chapter 5 moves south. In 'Latin America and the Caribbean: complicity and legacy of a long war', Juan Carlos Garzón and Ana María Rueda put forward the central argument that, in addition to the political agenda at both domestic and international levels, drug policies and the opportunities for their reform in Latin America and the Caribbean are mediated by institutional capacities and local conditions. This, the authors argue, makes it difficult to analyse the region - its advances and its setbacks - as a whole. Nonetheless, in relation to the international drug control regime, the complex combination of structural factors, especially the states' weaknesses, are key to understanding the acquiescence, defection and uncertainty of one of the most violent and unequal regions in the world. Drug policy, claim Garzón and Rueda, has overlooked these factors and, in some cases, has actually deepened vulnerabilities. Providing a broad overview of the policy landscape in the region, the chapter seeks to move beyond the traditional view of states in Latin America and the Caribbean as simple sites of production and transit and examine the complexity of drug-related issues including drug use - and related policy responses. It also demonstrates how illicit drug markets and reactions to them, including drug market related violence, are often connected to broader structural factors and relations with the US.

Chapter 6 brings discussion across the Atlantic. In 'Western and Central Europe: towards a cohesive model for drug policies?' Renaud Colson and Henri Bergeron show how, within Europe, the extent of drug use and drug trafficking vary greatly from region to region. This is also true of domestic drug policies which, against many indicators, are diverse. However, they argue, the deepening of the integration process of the continent and the rise of subnational actors in the design of local responses to drug issues have led to a progressive convergence. 
A policy discourse and a legal attitude that favour treating and reintegrating drug users, rather than depriving them of their liberty, has been developing at the transnational level. A cultural model for drug policy is emerging with enough cohesion to be able to claim that the European Union (EU) and European states (including EU neighbouring states) have reached shared positions on the political acceptability of harm reduction measures. Meanwhile medicinal cannabis is increasingly making inroads in the field of conventional medicine and several jurisdictions have been developing tolerant policies regarding recreational cannabis. In order to account for this dialectic of diversity and unity in the field of drug policy, Chapter 6 provides an overview of the drug issue and of the governance structure of drug policies in Europe. It begins with a review of the latest available figures on the prevalence of illicit drug use and the state of national markets, which show that Europe is not only a land of consumption and trafficking but also of production and exportation. The authors then demonstrate how the continental integration process and the rise of subnational actors, especially cities, has challenged the centrality of European states and led to the development of multilevel governance in the design of drug policies. Finally, the chapter identifies a cultural model of drug policy that favours treatment and reintegration of users rather than deprivation of their liberty. This model, in which harm reduction plays an important role, is now dominant in Europe even though variation between states still exists regarding legal penalties and sentencing practices that punish drug offences. The argument also turns the spotlight on various legal instruments, be they transnational, such as the EU response to NPS, or national, such as the Portuguese decriminalization experience, which, it is claimed, demonstrate that Europe is a place of innovation in the field of drug policy.

Chapter 7 shifts attention to geographically adjacent regions, but ones with a very different approach to drug policy. In 'Documenting human rights violations is not enough to reform archaic drug policies in Eastern Europe and Central Asia', Mikhail Golichenko focuses on the 15 now-independent states of the former Union of Soviet Socialist Republics (USSR), which rooted in their common Soviet past, form the core of Eastern Europe and Central Asia (EECA). As Golichenko explains, this is a region with a fast-growing HIV epidemic, archaic punitive drug policies and one where Russian drug policy positions influence debates. As such, understanding the main obstacles for drug policy reforms in EECA requires knowledge of the factors stifling drug policy reforms in Russia. The chapter examines Russia's drug policy and attempts to answer such questions as why Ukraine, for example, maintains the region's most draconian laws concerning the possession of opioids, despite being the most successful in implementing harm reduction; why people who inject drugs are most affected by HIV in Kyrgyzstan despite the availability of all nine harm reduction interventions; or why there is a strong opposition to opioid substitution therapy (OST) in Kazakhstan despite obvious positive results of OST pilot programmes there and in neighbouring countries.

In Chapter 8, 'Drug policy in Africa: a history of global and regional dynamics', Neil Carrier and Gernot Klantschnig explain how Africa has a long history of drug production, trade and consumption, and as a consequence a long history of debates about how such substances should be controlled within society. However, it is argued, it was in the colonial era that most drug laws within Africa were first enacted, often following blueprints from other parts of the world rather than reflecting actual usage and concerns of Africans. Within this context, the chapter traces the origins of African drug policies within its colonial history, and the intertwining of policy in Africa with global policy developments. The authors suggest how, despite the globalization of such policy, the situation in Africa is very varied as different 
countries adapt and interpret such policies in different ways. The chapter explores how several African countries are now moving away from prohibitionist policy, especially in relation to cannabis, and how debate is growing for change despite much pushback at the level of national and regional politics.

Stepping away from the singular use of geographical units as an organization framework, Chapter 9 is titled 'Drug use, policies and prohibition in Muslim countries'. Here Khalid Tinasti describes how national laws within Muslim countries apply particularly punitive policies in response to drug use and possession. Legal responses are based on religious doctrine prohibiting the consumption of mind-altering substances, but such states also share similarities beyond religion or language. These include a lack of democratic rule or independent and democratic judiciary. They nevertheless face different challenges linked to the use, production or transit of illegal drugs, and are part of different regional groups (from West Africa to South East Asia). Within this context, the chapter uses a multidisciplinary approach to analyse policies on drug use in Muslim countries. It covers three main regions: North Africa, the Middle East, and the Golden Crescent and, focusing on provisions institutionalizing prohibition as the sole response to the illicit market, aims to provide the reader with a comprehensive overview of policies and practice in the Muslim world. The chapter includes a section on the death penalty, since Muslim countries retain the highest rates of capital punishment for drug-related offences. It also incorporates discussion on the role of these countries in influencing drug policies beyond their borders.

Picking up on some of the themes within the previous chapter, Gloria Lai and Claudia Stoicescu move attention to Asia more broadly. In Chapter 10, 'Drug policy in Asia: the origins and extremities of prohibition', they reveal how the steady expansion of drug markets over the past two centuries is not unique to Asia. Nonetheless, it is argued, the extent of government control over individual drug consumption, along with the pace and scale of violence employed by governments in their drug enforcement efforts appears stark in comparison to other parts of the world. Lai and Stoicescu discuss how governments in the region stand out for retaining use of the death penalty for drug-related offences, compulsory detention as the chief mode of drug rehabilitation, and for state-sponsored campaigns of extrajudicial killing. The chapter analyses the historical development of drug policies and the nature of contemporary drug policies in the region with the aim of understanding the factors that sustain some of the harshest approaches to drugs in the world.

Deploying another regional approach and highlighting more progressive policy approaches, Amber Marks and Caitlin Hughes shift attention to Oceania. In Chapter 11, 'The changing tides of drug consumption, supply and drug policy in Oceania', the authors critically analyse use, production, supply and trafficking as well as key laws and policy responses across the region. The chapter shows that the prevalence of use is high in some parts of Oceania (notably Australia and New Zealand) and that whilst there remain large gaps in data monitoring capacity in most Pacific countries, there are clear indications that the Pacific countries are increasingly being used as transit trafficking routes to Australia and New Zealand. A wide range of policy responses are discussed, including the first jurisdiction in the world to legalize medical and recreational cannabis simultaneously (in the Commonwealth of Northern Mariana Islands); the first legislative framework for the lawful sale of psychoactive substances for recreational purposes (in New Zealand) and one of the longest adopters of cannabis decriminalization of personal use, possession and cultivation and police diversion programmes for use and possession of all illegal drugs (in Australia). 
Part III, 'Emerging tensions within the UN drug control system and beyond', returns to more explicit discussion of the international dimension. In so doing it highlights in various ways the 'intermestic' nature of the issue area and how, seldom sitting in a domestic policy silo, debates around drug policy are affected by and play out at different levels of governance.

In Chapter 12, 'The rise and fall of the "drug free world" narrative', Steve Rolles discusses how the prohibitionist paradigm that has dominated global drug policy thinking over the past century or more has long been premised on and specifically framed as the achievement of 'drug free' societies in key national and international policy positions. In recent decades, as the failings of enforcement-led drug control have become increasingly apparent, however, policy in many jurisdictions has moved towards more pragmatic public health approaches including policy and law reform. With this shift, Rolles argues, the historic pre-eminence of prevalence as an indicator of policy success or failure, has been questioned, alongside the utility of 'drug free' goals. Indeed, the chapter shows how trends in drug policy reform, including harm reduction, decriminalization and, more recently, legalization and regulation, have tended to adopt evaluative approaches that, whilst not precluding prevalence measures, also consider wider health and well-being outcome measures, as well as wider policy impacts regarding human rights, development and security. Dogmatic prioritization of unrealistic 'drug free' targets in this context are, it is claimed, unhelpful and have been increasingly marginalized. The tensions between the 'drug free' focus of historic prohibitionist thinking, and the broader based, and arguably pragmatic, approach of much contemporary drug policy reform is reflected in increasingly intense debate in domestic and international political arenas. The chapter shows how the UN has witnessed polarization between a growing group of pragmatic reform oriented member states and those advocating the status quo prohibitionist narratives. This is a situation, it concludes, reflected in their respective positions coexisting as increasingly uneasy conceptual bedfellows despite the evident contradictions.

Unpacking a key example of such contradictions, or at least the subject of varying interpretative positions, Chapter 13 is titled, 'Drug control and human rights: parallel universes, universal parallels'. Here Julie Hannah and Rick Lines examine the engagement and progress on human rights by the UN drug control regime from 2008 to 2018 through a comparative qualitative assessment of the official work of four principal political and normative institutions: the CND, the INCB, the Human Rights Council and the UN human rights treaty bodies. Breaking this ten-year period into three distinct stages, and using the 2016 UNGASS as a benchmark, the chapter demonstrates how human rights and drug policy is an issue that has achieved significant attention within these institutions, and provides a summary interpretation of these official records that enables scholars, policy-makers, and other students to better understand how this issue has evolved across each forum.

Moving onto a related set of issues, Chapter 14, 'Public health and international drug control: harm reduction and access to controlled medicines', sees Jennifer Hasselgard-Rowe, Naomi Burke-Shyne and Ann Fordham explore the centrality of, and tensions around, the pursuit of public health within the international drug control regime. Beginning with the 1961 UN Single Convention on Narcotic Drugs' preambular commitment to the 'health and welfare of mankind', the chapter explores efforts to advance what are argued to be two core health interventions under the Convention - namely harm reduction and access to internationally controlled essential medicines. With respect to harm reduction, the chapter examines the tensions that this 'approach' has generated within the international drug control regime and charts how, despite normative discord, harm reduction has over the years become less contentious. 
Today, it is broadly accepted that certain harm reduction interventions have been absorbed by the drug control regime. With respect to access to controlled medicines, the authors emphasize how the international community has struggled to balance the dual obligations under the Single Convention - the obligation of control and the obligation to ensure controlled medicines are available for medical and scientific use. This, it is posited, has resulted in a default focus on control. The chapter concludes that these tensions, together with the criminalization of drug use and possession, have constrained the pursuit of public health within what has primarily been a prohibitionist oriented international drug control framework, and this has been particularly apparent with regard to harm reduction and access to controlled medicines.

Revealing some parallels with problematic access to controlled medicines in some parts of the world, in Chapter 15, 'Drugs and development: drug policies and the Global South', Julia Buxton, discusses how, with its historical emphasis on supply containment and focus on plant rather than synthetic-based narcotics, the extant UN treaty framework is structurally biased against low- and middle-income countries (LMICs). LMICs, Buxton explains, carry a disproportionate responsibility for supply control and yet lack sovereignty in the design and implementation of domestic drug policies. This comes at a heavy financial and social cost to poor and unequal countries, with implication for development prospects. Taking a holistic approach to the drugs and development nexus in LMICs, and crucially examining development from a human perspective embracing enhanced freedom, opportunity and well-being, the chapter argues that those programmes intended to eliminate illegal cultivation, manufacture and trafficking are counter-productive in both 'hard' militarized and 'soft' alternative development forms and they have failed to reduce global drug volumes. It is also discussed how trends of rising drug consumption in LMICs have been met with repressive state responses and how, like coercive supply-side strategies, punitive approaches to demand control create an environment that is inimical to human security, fundamental rights and for the achievement of the SDGs.

Retaining focus on the 'Global South', in Chapter 16, 'Bolivia, coca, culture and colonialism', Zoe Pearson explores the significance of the coca plant to Bolivian and Andean societies for thousands of years as a natural food, medicine and object of spiritual importance. However, as she describes, in 1961 the international drug policy regime entrenched the demonization of the plant, also the main ingredient in cocaine, in the UN Single Convention on Narcotic Drugs, subsequently making violent eradication of coca an accepted method of carrying out supply-side drug control policy. Since the election of President Evo Morales, Bolivia has instituted comprehensive reforms to control coca supply within the country's borders and gained an exception to the 1961 Single Convention that sanctions traditional coca uses in Bolivia. As the chapter discusses, a central feature of Bolivia's new approach is community-based coca control that rejects the forced eradication approaches of the past. With this in mind, Pearson argues that the Bolivian case deserves greater attention in international drug policy reform debates, both because of the possibilities it engenders, and because of the challenges and tensions it produces.

Employing a similarly forward looking approach to recent policy shifts, Chapter 17 examines the relatively recent emergence of regulated cannabis markets for non-medical adult use. In 'Regulating cannabis in Uruguay, the United States and Canada: is a social justice framework possible?', Zara Snapp and Jorge Herrera Valderrábano aim to address a key and, within some quarters, increasingly pressing question: how can psychoactive substances be regulated within a social justice framework? As follow on issues for discussion, the authors also ask, 
from a policy reform perspective, how can we ensure that we are not only overturning the long-standing prohibition of cannabis (and other illegal psychoactive substances), but also dismantling the structural and systemic ways that governments have enforced unjust laws through discriminatory and discretional mechanisms? And, how do we integrate comprehensive reparations into regulatory models? Within this context, the chapter explores the legal regulation of cannabis in three states in the US, as well as at the national level in Uruguay and Canada, as a means of understanding the historical path taken and gleaning lessons for other jurisdictions that seek to implement regulations of psychoactive substances with a social justice focus. Once again indicating the close connection between domestic policy and the international drug control regime, it also touches upon the diverse positions taken by these countries to defend their international obligations regarding the drug control conventions.

In Part IV, 'Future challenges', the final chapters move to address some important issues of growing concern, in terms of both shifting market dynamics and appropriate policy responses, including the measurement of policy success.

In Chapter 18, 'The search for new drug policy metrics', Nazlee Maghsoudi, Justine Tanguay and Dan Werb build upon some of the ideas presented by Rolles in Chapter 12 . Highlighting the essential fact that good data is indispensable for effective policy, the chapter discusses the important role that numbers and metrics play in the formulation, implementation and evaluation of drug policy around the world, but particularly within the overarching international drug control framework. The authors examine how currently dominant process and output indicators measuring, for example, drug crop eradication, seizures and arrests, are problematic and discuss the growing debates around the need for more appropriate outcome indicators. The chapter discusses how some states are moving towards a greater focus on the health and human security of individuals and communities and how such shifts are being replicated, or otherwise, at the UN level. Discussion also considers not only the disconnect between current indicators and a market-management approach to dealing with illicit drug markets, but also the growing awareness in some quarters of the links between SDG indicators and drug policy evaluation.

In Chapter 19, 'The NPS imposters, merging and emerging drug markets and the contribution of drug checking', Fiona Measham discusses NPS. Initially called 'legal highs', the NPS category incorporates the many hundreds of synthetic and herbal psychoactive substances that have appeared in the last ten years or so around the world and present a significant challenge for existing forms of international drug control. Providing both an overview of patterns, prevalence and motivations for use in the UK and an overview of key trends, Measham teases out the relationship between science, policy and politics in the control of NPS, as well as their wider significance to drug policy and research. Although prevalence of NPS use remains low by comparison with established controlled drugs in most countries, the significance of the emergence of NPS relates to the rapidity of innovation, the speed and scale of policy responses, and the pivotal role of new information and communication technologies in establishing a global market. In contrast with established controlled drugs, the chapter argues, regulatory regimes have been quick to respond to the perceived threat from NPS, the scale of which has led to innovation in legislative control, as well as in policy responses, research and evaluation. The themes of international innovation and collaboration are mirrored in research methods too, for example, with the growth of forensic early warning systems, waste-water analysis and drug safety testing (or 'drug checking'). The chapter concludes by discussing the value of drug safety testing for monitoring NPS trends through its distinct ability to measure the extent of 
the disparity between acquisitions and expectations in illegal drug sales and, with increased regulatory control of NPS, the merging of NPS and established drug markets. Drawing on data from the UK's first and only dedicated drug safety testing service, the example of MDMA is discussed to illustrate these issues.

And finally, in Chapter 20, 'Drug cryptomarket futures: structure, function and evolution in response to law enforcement actions', Patrick Shortis, Judith Aldridge and Monica J. Barratt examine how developments in encryption technology have facilitated new forms of digital drug trading. The authors provide an overview of cryptomarkets and the technologies that underpin them with examination of the history of cryptomarket development demonstrating that they have evolved in response to enforcement operations and threats from within the community. Nonetheless, as is shown, policy responses, whilst increasingly varied and sophisticated, remain in line with prohibition and suppression. The evaluation of the transformative potential of cryptomarkets on the global drugs trade provided by Shortis, Aldridge and Barratt suggests it is limited to specific drugs, countries and forms of violence, and that its impact will be greater in countries where drug consumption is highest rather than traditional producer countries like Colombia or Afghanistan. Whilst the literature is emergent, the authors argue that it demands better scrutiny from law enforcement and policy-makers in designing appropriate responses to the online drugs trade to avoid unintentionally increasing harms both for drug takers and the public.

As will be clear, the chapters included in this Research Handbook highlight not only existing barriers, complexities and challenges, but also in many instances opportunities for the reform of drug policies. While the authors cover a wide range of issues, they point to many of the same themes and issues, with their positions, conclusions and stances all informed by evidence rather than dogma. The volume, published a decade ahead of the target date for the achievement of the SDGs and nine years before the next scheduled international political agreement currently underpinned by the goal to eliminate or significantly reduce the scale of the illegal drug market at a global level, draws attention to the myriad costs to contemporary societies of drug policy dominated by punitive prohibition. It also highlights the benefits to be gained by public health and rights based approaches; approaches that intersect in many ways with the SDGs. It is our hope that beyond highlighting many of the key issues of ongoing concern and advancing the research agenda, the Research Handbook will make a positive contribution to increasingly important policy debates and help ensure the centrality of individuals and the communities within which they live.

\section{REFERENCES}

Andreas, P. \& Nadelmann, E. (2006), Policing the Globe: Criminalization and Crime Control in International Relations, Oxford University Press.

Babor, T. F. et al. (2018), Drug Policy and the Public Good (second edition), Oxford University Press. Bewley-Taylor, D. R. (2016), Towards Metrics that Measure Outcomes that Matter, Global Drug Policy Observatory Policy Brief 10, Swansea University, Swansea, UK.

Bewley-Taylor, D. R. (2012), International Drug Control: Consensus Fractured, Cambridge University Press.

Bewley-Taylor, D. R., Jelsma, M. \& Blickman, T. (2014), The Rise and Decline of Cannabis Prohibition: The History of Cannabis in the UN Drug Control System and Options for Reform, Transnational Institute-Global Drug Policy Observatory, Amsterdam-Swansea. 
Boister, N. (2016), 'Waltzing on the Vienna Consensus on Drug Control? Tensions in the International System for the Control of Drugs', Leiden Journal of International Law, 29, pp. 389-409.

Christie, N. \& Bruun, K. (1991), Der Nuetzliche Feind: Die Drogenpolitik and ihre Nutzniesser, AJZ Verlag, Bielefeld (cited in Gerber, J. \& Jensen, E. L. (Eds) (2001), Drug War American Style. The internationalization of Failed Policy and its Alternatives, Garland Publishing, New York and London).

Costa, A. M. (2008), Making Drug Control 'Fit for Purpose': Building on the UNGASS Decade, Statement of the Executive Director of the UNODC.

Coulson, R. (2019), 'Fixing Transnational Drug Policy: Drug Prohibition in the Eyes of Comparative Law', Journal of Law and Society, 46(S1), pp. S73-S94.

Eastwood, N., Fox, E. \& Rosmarin, A. (2016), A Quiet Revolution: Drug Decriminalisation Across the Globe, Release Publication, London, UK.

Girelli, G. (2019), The Death Penalty for Drug Offences: Global Overview 2018. Harm Reduction International, London, UK. Available from https://www.hri.global/death-penalty-drugs-2018 (accessed 11 June 2020).

International Drug Policy Consortium (IDPC) (2019), The 2019 Commission on Narcotic Drugs and its Ministerial Segment. Taking Stock of the Implementation of the Commitments Made Jointly to Address and Counter the World Drug Problem, in Particular in Light of the 2019 target date, IDPC, London, UK.

International Drug Policy Consortium (IDPC)-Global Drug Policy Observatory (GDPO) (2019), The World Drug Report 2019: Perspectives on Protecting Public Health, IDPC \& GDPO, LondonSwansea, UK.

INCB (2020), Report of the International Narcotics Control Board for 2019, United Nations, Vienna.

Pollack, H. A. \& Reuter, P. (2014), 'Does Tougher Enforcement Make Drugs More Expensive?', Addiction, 109(12), pp. 1959-1966.

Tinasti, K. \& Barbosa, I. (2017), 'The Influence of Global Players on the Drug Control System: An Analysis of the Role of the Russian Federation', Drugs and Alcohol Today, 17(2), pp. 124-134.

UN (2019) Ministerial Declaration on Strengthening our Actions at National, Regional and International Levels to Accelerate the Implementation of our Joint Commitments to Counter and Address the World Drug Problem. Available from https://www.unodc.org/documents/commissions/CND/2019 Ministerial_Declaration.pd (accessed 11 June 2020).

UNODC (2019), World Drug Report 2019, Booklet 1, Executive Summary, Conclusions and Policy Implications (United Nations publication, Sales No. E.19.XI.8).

Werb, D., Rowell, G., Guyatt, G., Kerr, T., Montaner, J. \& Wood, E. (2011), 'Effect of Drug Law Enforcement on Drug Market Violence: A Systematic Review', International Journal of Drug Policy, 22(2), pp. 87-94. 